Discussion

\title{
Towards a consensus on developmental regression
}

Dajie Zhang ${ }^{\mathrm{a}, \mathrm{b}, \mathrm{c}}$, Francesco Bedogni ${ }^{\mathrm{d}}$, Sofie Boterberg ${ }^{\mathrm{e}}$, Carol Camfield ${ }^{\mathrm{f}}$, Peter Camfield ${ }^{\mathrm{f}}$, Tony Charman ${ }^{\mathrm{g}, \mathrm{h}}$, Leopold Curfs ${ }^{\mathrm{i}}$, Christa Einspieler ${ }^{\mathrm{b}}$, Gianluca Esposito ${ }^{\mathrm{j}, \mathrm{k}}$, Bianca De Filippis ${ }^{1}$, Robin P. Goin-Kochel $^{\mathrm{m}, \mathrm{n}}$, Günter U Höglinger ${ }^{\mathrm{o}, \mathrm{p}, \mathrm{q}}$, Daniel Holzinger ${ }^{\mathrm{r}, \mathrm{s}}$, Ana-Maria Iosif ${ }^{\mathrm{t}}$, Giulio E. Lancioni ${ }^{\mathrm{u}}$, Nicoletta Landsberger ${ }^{\mathrm{d}}$, Giovanni Laviola ${ }^{\mathrm{l}}$, Eva M. Marcov ${ }^{\mathrm{v}}$, Michael Müller ${ }^{\mathrm{w}}$, Jeffrey L. Neul ${ }^{\mathrm{x}}$, Karin Nielsen-Saines ${ }^{\mathrm{y}}$, Anders Nordahl-Hansen ${ }^{\mathrm{z}}$, Mark F. O'Reilly ${ }^{\mathrm{A}}$, Sally Ozonoff ${ }^{\mathrm{B}}$, Luise Poustka ${ }^{\mathrm{a}, \mathrm{c}}$, Herbert Roeyers ${ }^{\mathrm{e}}$, Marija Rankovic ${ }^{\mathrm{C}}$, Jeff Sigafoos ${ }^{\mathrm{D}}$, Kristiina Tammimies $^{\mathrm{E}}$, Gillian S Townend ${ }^{\mathrm{i}}$, Lonnie Zwaigenbaum ${ }^{\mathrm{F}}$, Markus Zweckstetter ${ }^{\mathrm{C}, \mathrm{G}}$, Sven Bölte ${ }^{\mathrm{E}, \mathrm{H}}$, Peter B Marschik ${ }^{\mathrm{a}, \mathrm{b}, \mathrm{c}, \mathrm{E}, *}$

${ }^{a}$ Department of Child and Adolescent Psychiatry and Psychotherapy, University Medical Center Goettingen, Goettingen, Germany

b $i D N$ - interdisciplinary Developmental Neuroscience, Division of Phoniatrics, Medical University of Graz, Graz, Austria

${ }^{\mathrm{c}}$ Leibniz ScienceCampus Primate Cognition, Goettingen, Germany

${ }^{\mathrm{d}}$ Neuroscience Division, IRCCS San Raffaele Scientific Institute, Milan, Italy

${ }^{\mathrm{e}}$ Department of Experimental Clinical and Health Psychology, Faculty of Psychology and Educational Sciences, Ghent University, Ghent, Belgium

${ }^{\mathrm{f}}$ Department of Pediatrics, Dalhousie University and the IWK Health Centre, Canada

${ }^{\mathrm{g}}$ Department of Psychology, Institute of Psychiatry, Psychology \& Neuroscience, King's College London, London, UK

${ }^{\mathrm{h}}$ South London and Maudsley NHS Foundation Trust, London, UK

${ }^{\mathrm{i}}$ Rett Expertise Centre-GKC, Maastricht University Medical Centre, Maastricht, the Netherlands

${ }^{\mathrm{j}}$ Social \& Affiliative Neuroscience Lab, Psychology Program, Nanyang Technological University, Singapore

${ }^{\mathrm{k}}$ Affiliative Behaviour \& Physiology Lab, Department of Psychology and Cognitive Sciences, University of Trento, Trento, Italy

${ }^{1}$ Center for Behavioral Sciences and Mental Health, Istituto Superiore di Sanità, Rome, Italy

${ }^{\mathrm{m}}$ Department of Pediatrics, Baylor College of Medicine, Houston, TX, USA

${ }^{\mathrm{n}}$ Autism Center, Texas Children's Hospital, Houston, TX, USA

${ }^{\circ}$ German Center for Neurodegenerative Diseases (DZNE), Munich, Germany

${ }^{\mathrm{p}}$ Department of Neurology, Klinikum rechts der Isar, Technical University of Munich, Germany

${ }^{\mathrm{q}}$ Department of Neurology, Hannover Medical School, Hannover, Germany

${ }^{\mathrm{r}}$ Hospital of St. John of God, Institute for Neurology of Senses and Language, Linz, Austria

${ }^{\mathrm{s}}$ Research Institute for Developmental Medicine, Johannes Kepler University Linz, Linz, Austria

${ }^{\mathrm{t}}$ Department of Public Health Sciences, University of California, Davis, Davis CA, USA

${ }^{\mathrm{u}}$ Department of Neuroscience and Sense Organs, University of Bari, Bari, Italy

${ }^{v}$ Department of Genetics, Physiology and Microbiology, Faculty of Biological Sciences, Universidad Complutense de Madrid, Madrid, Spain

${ }^{\mathrm{w}}$ Institute of Neuro- and Sensory Physiology, University Medical Center Goettingen, Georg-August-University Goettingen, Germany

${ }^{\mathrm{x}}$ Vanderbilt Kennedy Center, Nashville, TN, USA

${ }^{\mathrm{y}}$ Department of Pediatrics, David Geffen School of Medicine, University of California, Los Angeles, CA, USA

${ }^{\mathrm{z}}$ Faculty of Education, Østfold University College, Halden, Norway

${ }^{A}$ Department of Special Education, University of Texas at Austin, Austin TX, USA

${ }^{\mathrm{B}}$ Department of Psychiatry and Behavioral Sciences, MIND Institute, University of California, Davis, Sacramento CA, USA

${ }^{\mathrm{C}}$ Department for NMR-based Structural Biology, Max Planck Institute for Biophysical Chemistry, Goettingen, Germany

${ }^{\mathrm{D}}$ School of Education, Victoria University of Wellington, Wellington, New Zealand

${ }^{\mathrm{E}}$ Center of Neurodevelopmental Disorders (KIND), Division of Neuropsychiatry, Centre for Psychiatry Research, Department of Women's and Children's Health, Karolinska Institutet, Stockholm, Sweden

${ }^{\mathrm{F}}$ Department of Pediatrics, University of Alberta, Edmonton, Canada

${ }^{\mathrm{G}}$ German Center for Neurodegenerative Diseases (DZNE), Goettingen, Germany

${ }^{\mathrm{H}}$ Curtin Autism Research Group, School of Occupational Therapy, Social Work and Speech Pathology, Curtin University, Perth, Western Australia, Australia

Despite intensive research for many years, developmental regression remains a puzzling phenomenon. Scientific and clinical interest in this topic increases steadily and is likely to persist in the upcoming years. Among the reasons are novel evidence of higher than previously assumed occurrence of developmental regression in some disorders, particularly early regression during the first year of life in autism

\footnotetext{
* Corresponding author at: Department of Child and Adolescent Psychiatry and Psychotherapy, University Medical Center Goettingen, Goettingen, Germany.

E-mail addresses: peter.marschik@medunigraz.at, peter.marschik@med.uni-goettingen.de (P.B. Marschik).
} 
spectrum disorder (ASD), a change in view of the nature of regression in specific disorders such as Rett syndrome (RTT), the growing understanding of aetiological mechanisms, protective, and causal factors of regression, and the necessity to develop effective interventions dealing with the dramatic loss of skills (e.g., Boterberg et al., 2019; Ozonoff and Iosif, 2019; Thurm et al., 2018).

Developmental regression has been defined as loss of previously acquired skills not caused by brain injury or other traumatic events. As yet, there is no consensus on how this definition of 'regression' should be operationalized, nor do standard measurements to capture developmental regression and its antecedents exist. There is only a restricted body of knowledge about the onset of regression and even less is known about the divergent pathways of regression and the severity of affected developmental domains. In clinical practice and research, it is not always possible to precisely and thoroughly document the achievement of skills, the onset of their loss, and the developmental trajectory before and following the skill loss. An ideal approach to document regressive functions would involve applying closely meshed multidimensional prospective assessments over time starting prior to regression. This works for some disorders when studying high-risk cohorts (e.g., ASD sibling studies; e.g., Bölte et al., 2013; Varcin and Jeste, 2017), but is not applicable to (rare) disorders for which such cohorts are unfeasible to obtain (e.g., RTT, Landau Kleffner syndrome, Phelan McDermid syndrome). Retrospective assessments (e.g., anamnestic assessments, questionnaires or checklists, retrospective audio-video analysis), on the other hand, are inherently adulterated by well-known memory or sampling bias, leaving the assumption of attaining or losing skills equivocal (e.g., Boterberg et al., 2019; Marschik and Einspieler, 2011). When it comes to defining the severity of regression or its representation, i.e. the partial or complete loss of functions, we are entering even less understood and researched grounds. Although the use of this terminology is widespread, a precise definition, again, is still absent. After all, without being able to specify characteristics and pathways prior to regression in terms of quality, quantity, time and timing, definitions of partial loss are fated to be vague and heterogeneous. The same challenge holds true for the definition of the phenomenological onset, the differentiation between transient or persisting regressive trajectories, as well as our understanding of improvement or 'recovery'.

According to recent studies (Ozonoff et al., 2018; Pearson et al., 2018), when applying dimensional (in contrast to categorical) methods to measure regression, most children diagnosed with autism experience a regression in social functions from 6 months onwards with a decreasing rate of expected social behaviours. Before 6 months of age, children later diagnosed with autism did not seem to differ from their typically developing peers in overt social behaviours (Elsabbagh et al., 2014; Landa and Garrett-Mayer, 2006; Ozonoff et al., 2010; Rozga et al., 2011; Young et al., 2009; Zwaigenbaum et al., 2005), giving the impression that the initial development of these infants might be intact. However, recent research suggests an array of atypical signs related to, and, beyond the social domain detectable by 6 months in infants who later develop autism (e.g., oculo-motor functions, motor behaviour, visual perception, vocalizations, and their underlying neural structure and functions; Bhat et al., 2012; Bosl et al., 2018; Brisson et al., 2014; Einspieler et al., 2014; Estes et al., 2015; Iverson et al., 2019; Jones and Klin, 2013; Paul et al., 2011; Wolff et al., 2012). Notably, observable social behaviours (e.g., orienting toward or scanning of socially relevant audio and visual information) that appear similar between young infants with and without ASD may rely on disparate neural mechanisms (e.g., Blasi et al., 2015; Braukmann et al., 2018; Elsabbagh et al., 2012; Lloyd-Fox et al., 2018). Learning from studies with RTT, the ostensible normal pre-regression development is marked by genuine atypicalities from the first months of life (Einspieler and Marschik, 2019, for a review). That said, even if we reach consensus on an operational definition based on gold standard assessments for regression for specific disorders, we are compelled to decrypt the nature of this puzzle whether it is a slant-down from typical development, or it is a manifestation of actual deviation in origin which emerges subtly and divulges itself only when the individual capacity could no longer meet the age-appropriate behavioural demands or expectations? The solution but also the challenge remains to better understand and characterize the enigmatic pre-regression period.

To date, the precise origins of regression are still largely unknown but probably linked to a complex interaction between biological and environmental factors. Future research will benefit from a constructivist approach to encompass knowledge on structural and functional development of single disorders, and tackle similarities and dissimilarities across-syndromes. On the one hand, we need to search for disorder causing mechanisms, disorder promoting and protective factors, and the structural underpinnings of various functional representations. On the other hand, we need to try to rigorously define and characterize the acquisition and loss of behavioural representations of altered neurobiological causes. The increasingly sophisticated understanding of pathogenic liabilities of regression (e.g., Thurm et al., 2018) will help us to decipher deteriorating development, the pathways to it, and the ways beyond.

\section{Conclusion}

Developmental regression is a complex phenomenon seen in several developmental disorders and needs to be defined by objective and dimensional parameters that specify its measurement, prevalence, age of onsets, key profiles, and pathways for each single disorder. To resolve the puzzle of regression, long-term cross-disciplinary efforts are necessary to define the loss of acquired skills, functions, and capacities before and after its onset. Only concerted research efforts and a synthesis of knowledge from different scientific disciplines and approaches will allow to essentially move this field forward. More specifically, we need to determine what are the possible impacts of some very early acquired or absent skills on the development of other functions within and across early neurodevelopmental domains during the infancy period that is characterised by rapid brain and behavioural development. A consensus operational definition of developmental regression and recommendations for measurement will set the start to decipher its neurological underpinnings, unfolding trajectories, and cross-domain impact. This might in return refine our initial understanding of regression and hence enable more targeted early interventions.

\section{Acknowledgements}

We would like to sincerely thank all contributors to the special issue on developmental regression in this Journal, all reviewers and colleagues who discussed this important topic with us and who will further develop the better understanding of regression. PBM was supported by FWF (P25241, TCS24), OeNB (P16430) and the Bill and Melinda Gates Foundation Grand Challenges Exploration Grant (OPP 1128871). Initiating discussions were supported by a "Think Tank Symposium" through the Leibniz ScienceCampus Primate Cognition.

\section{References}

Bhat, A.N., Galloway, J.C., Landa, R.J., 2012. Relation between early motor delay and later communication delay in infants at risk for autism. Infant Behav. Dev. 35, $838-846$.

Blasi, A., Lloyd-Fox, S., Sethna, V., Brammer, M.J., Mercure, E., Murray, L., Williams, S.C., Simmons, A., Murphy, D.G., Johnson, M.H., 2015. Atypical processing of voice sounds in infants at risk for autism spectrum disorder. Cortex 71, 122-133.

Bölte, S., Marschik, P.B., Falck-Ytter, T., Charman, T., Roeyers, H., Elsabbagh, M., 2013. Infants at risk for autism: a European perspective on current status, challenges and opportunities. Eur. Child Adolesc. Psychiatry 22, 341-348.

Bosl, W.J., Tager-Flusberg, H., Nelson, C.A., 2018. EEG analytics for early detection of autism spectrum disorder: a data-driven approach. Sci. Rep. 8, 6828.

Boterberg, S., Charman, T., Marschik, P.B., Bolte, S., Roeyers, H., 2019. Regression in autism spectrum disorder: a critical overview of retrospective findings and recommendations for future research. Neurosci. Biobehav. Rev. 102, 24-55. 
Braukmann, R., Lloyd-Fox, S., Blasi, A., Johnson, M.H., Bekkering, H., Buitelaar, J.K., Hunnius, S., 2018. Diminished socially selective neural processing in 5-month-old infants at high familial risk of autism. Eur. J. Neurosci. 47, 720-728.

Brisson, J., Martel, K., Serres, J., Sirois, S., Adrien, J.L., 2014. Acoustic analysis of ora productions of infants later diagnosed with autism and their mother. Infant Ment. Health J. 35, 285-295.

Einspieler, C., Marschik, P.B., 2019. Regression in Rett syndrome: Developmental pathways to its onset. Neurosci. Biobehav. Rev. 98, 320-332.

Einspieler, C., Sigafoos, J., Bölte, S., Bratl-Pokorny, K.D., Landa, R., Marschik, P.B., 2014. Highlighting the first 5 months of life: General movements in infants later diagnosed with autism spectrum disorder or Rett Syndrome. Res. Autism Spectr. Disord. 8, 286-291.

Elsabbagh, M., Bedford, R., Senju, A., Charman, T., Pickles, A., Johnson, M.H., 2014. What you see is what you get: contextual modulation of face scanning in typical and atypical development. Soc. Cogn. Affect. Neurosci. 9, 538-543.

Elsabbagh, M., Mercure, E., Hudry, K., Chandler, S., Pasco, G., Charman, T., Pickles, A., Baron-Cohen, S., Bolton, P., Johnson, M.H., 2012. Infant neural sensitivity to dynamic eye gaze is associated with later emerging autism. Curr. Biol. 22, 338-342.

Estes, A., Zwaigenbaum, L., Gu, H., St John, T., Paterson, S., Elison, J.T., Hazlett, H., Botteron, K., Dager, S.R., Schultz, R.T., Kostopoulos, P., Evans, A., Dawson, G., Eliason, J., Alvarez, S., Piven, J., 2015. Behavioral, cognitive, and adaptive development in infants with autism spectrum disorder in the first 2 years of life. J. Neurodev. Disord. 7, 24

Iverson, J.M., Shic, F., Wall, C.A., Chawarska, K., Curtin, S., Estes, A., Gardner, J.M., Hutman, T., Landa, R.J., Levin, A.R., Libertus, K., Messinger, D.S., Nelson, C.A., Ozonoff, S., Sacrey, L.R., Sheperd, K., Stone, W.L., Tager-Flusberg, H.B., Wolff, J.J., Yirmiya, N., Young, G.S., 2019. Early motor abilities in infants at heightened versus low risk for ASD: a Baby Siblings Research Consortium (BSRC) study. J. Abnorm. Psychol. 128, 69-80.

Jones, W., Klin, A., 2013. Attention to eyes is present but in decline in 2-6-month-old infants later diagnosed with autism. Nature 504, 427-431.

Landa, R., Garrett-Mayer, E., 2006. Development in infants with autism spectrum disorders: a prospective study. J. Child Psychol. Psychiatry 47, 629-638.

Lloyd-Fox, S., Blasi, A., Pasco, G., Gliga, T., Jones, E.J.H., Murphy, D.G.M., Elwell, C.E., Charman, T., Johnson, M.H., 2018. Cortical responses before 6 months of life associate with later autism. Eur. J. Neurosci. 47, 736-749.

Marschik, P.B., Einspieler, C., 2011. Methodological note: video analysis of the early development of Rett syndrome-one method for many disciplines. Dev. Neurorehabil.
14, 355-357.

Ozonoff, S., Gangi, D., Hanzel, E.P., Hill, A., Hill, M.M., Miller, M., Schwichtenberg, A.J., Steinfeld, M.B., Parikh, C., Iosif, A.M., 2018. Onset patterns in autism: variation across informants, methods, and timing. Autism Res. 11, 788-797.

Ozonoff, S., Iosif, A.M., 2019. Changing conceptualizations of regression: what prospective studies reveal about the onset of autism spectrum disorder. Neurosci. Biobehav. Rev. 100, 296-304.

Ozonoff, S., Iosif, A.M., Baguio, F., Cook, I.C., Hill, M.M., Hutman, T., Rogers, S.J., Rozga, A., Sangha, S., Sigman, M., Steinfeld, M.B., Young, G.S., 2010. A prospective study of the emergence of early behavioral signs of autism. J. Am. Acad. Child Adolesc. Psychiatry 49, 256-266 e251-252.

Paul, R., Fuerst, Y., Ramsay, G., Chawarska, K., Klin, A., 2011. Out of the mouths of babes: vocal production in infant siblings of children with ASD. J. Child Psychol. Psychiatry $52,588-598$.

Pearson, N., Charman, T., Happe, F., Bolton, P.F., McEwen, F.S., 2018. Regression in autism spectrum disorder: reconciling findings from retrospective and prospective research. Autism Res. 11, 1602-1620.

Rozga, A., Hutman, T., Young, G.S., Rogers, S.J., Ozonoff, S., Dapretto, M., Sigman, M., 2011. Behavioral profiles of affected and unaffected siblings of children with autism: contribution of measures of mother-infant interaction and nonverbal communication. J. Autism Dev. Disord. 41, 287-301.

Thurm, A., Powell, E.M., Neul, J.L., Wagner, A., Zwaigenbaum, L., 2018. Loss of skills and onset patterns in neurodevelopmental disorders: understanding the neurobiological mechanisms. Autism Res. 11, 212-222.

Varcin, K.J., Jeste, S.S., 2017. The emergence of autism spectrum disorder: insights gained from studies of brain and behaviour in high-risk infants. Curr. Opin. Psychiatry 30, 85-91.

Wolff, J.J., Gu, H., Gerig, G., Elison, J.T., Styner, M., Gouttard, S., Botteron, K.N., Dager, S.R., Dawson, G., Estes, A.M., Evans, A.C., Hazlett, H.C., Kostopoulos, P., McKinstry, R.C., Paterson, S.J., Schultz, R.T., Zwaigenbaum, L., Piven, J., 2012. Differences in white matter fiber tract development present from 6 to 24 months in infants with autism. Am. J. Psychiatry 169, 589-600.

Young, G.S., Merin, N., Rogers, S.J., Ozonoff, S., 2009. Gaze behavior and affect at 6 months: predicting clinical outcomes and language development in typically developing infants and infants at risk for autism. Dev. Sci. 12, 798-814.

Zwaigenbaum, L., Bryson, S., Rogers, T., Roberts, W., Brian, J., Szatmari, P., 2005. Behavioral manifestations of autism in the first year of life. Int. J. Dev. Neurosci. 23, 143-152. 